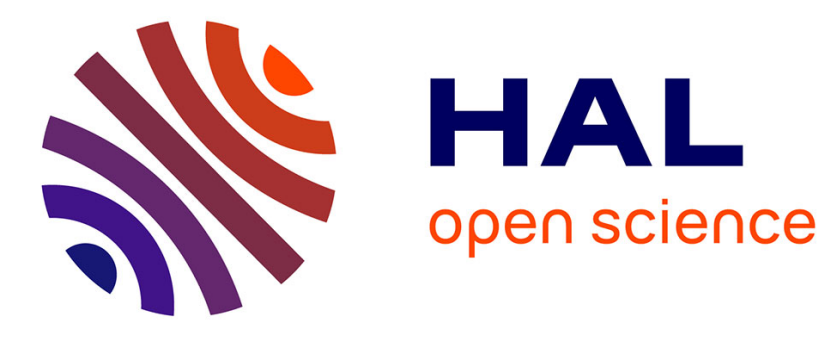

\title{
Optical study of annealed cobalt-porous silicon nanocomposites
}

\author{
Montassar Billeh Bouzourâa, Mehdi Rahmani, Mohamed-Ali Zaïbi, Nathalie \\ Lorrain, Lazhar Haji, Mehrezi Oueslati
}

\section{- To cite this version:}

Montassar Billeh Bouzourâa, Mehdi Rahmani, Mohamed-Ali Zaïbi, Nathalie Lorrain, Lazhar Haji, et al. Optical study of annealed cobalt-porous silicon nanocomposites. Journal of Luminescence, 2013, 143, pp.521-525. 10.1016/j.jlumin.2013.05.050 . hal-00840826

\section{HAL Id: hal-00840826 https://hal.science/hal-00840826}

Submitted on 4 Jul 2013

HAL is a multi-disciplinary open access archive for the deposit and dissemination of scientific research documents, whether they are published or not. The documents may come from teaching and research institutions in France or abroad, or from public or private research centers.
L'archive ouverte pluridisciplinaire HAL, est destinée au dépôt et à la diffusion de documents scientifiques de niveau recherche, publiés ou non, émanant des établissements d'enseignement et de recherche français ou étrangers, des laboratoires publics ou privés. 


\title{
Optical study of annealed cobalt - porous silicon nanocomposites
}

\author{
M-B Bouzourâa ${ }^{(1)}$, M. Rahmani*(1) , M.-A Zaïbi ${ }^{(1 \& 2)}$, N. Lorrain $^{(3)}$, L. Hajji ${ }^{(3)}$, M. Oueslati ${ }^{(1)}$ \\ (1) Unité de Spectroscopie Raman, Faculté des Sciences de Tunis, Département de Physique, 2092 El \\ Manar, Tunis - Tunisia \\ (2) Ecole Supérieure des Sciences et Techniques de Tunis, 5 Avenue Taha Hussein, 1008 Tunis - \\ Tunisia. \\ (3) Université Européenne de Bretagne, CNRS FOTON-UMR 6082, 6 rue de Kérampont, BP 80518, \\ 22305 Lannion Cedex, France. \\ * Corresponding author: Tel: (+216)27810093 / Fax: $(+216) 71885073$ \\ E-mail: rahmanimehdi79@yahoo.com
}

\begin{abstract}
We report Raman and photoluminescence studies of cobalt - porous silicon nanocomposites (PS/Co). Cobalt was introduced in porous silicon (PS) by immersion method using $\mathrm{CoCl}_{2}$ aqueous solution. The presence of cobalt in PS matrix was identified by FTIR spectroscopy and EDX analyses. The Raman spectroscopy revealed the presence of Si bonded to cobalt oxide in PS/Co. We discuss also the Raman spectra of PS and PS/Co samples under different annealing temperatures ranging from room temperature (RT) to $600^{\circ} \mathrm{C}$. The optical properties of PS and PS/Co were studied by photoluminescence (PL). The highest PL intensity was observed for an immersion time of $60 \mathrm{~min}$. For long duration, the deposited cobalt quantity acts as energy trap and promotes the non-radiative energy transfer; it is the autoextinction phenomenon. We have studied also the effect of the annealing temperature on the PL of both PS and PS/Co samples. For PS, the annealing process leads to a rapid oxidation of the Si nanocrystallites (nc-Si). In the case of PS/Co sample, two different mechanisms are proposed; one is the desorption of $\mathrm{Si}-\mathrm{H}_{\mathrm{x}(\mathrm{x}=2,3)}$ with the formation of cobalt oxide for annealing temperature less than $450^{\circ} \mathrm{C}$ which causes the increasing of PL intensity and the stability of PL energy, the other mechanism is the transformation of the porous silicon to silica at high temperatures $\left(\succ 450^{\circ} \mathrm{C}\right)$ which leads to the decreasing of the PL intensity and the blue shift of the PL curve.
\end{abstract}

Keywords: Porous silicon, Cobalt, Raman, Photoluminescence, Annealing temperature. 


\section{1- Introduction}

The highly efficient luminescence of porous silicon at room temperature [1] makes it an interesting material for various applications in optoelectronic devices like light emitting diodes (LED).

The doping of porous silicon with some kind of metals is essential for the creation of nanocomposites with multifunctional properties. Indeed, transition-metal ions such as $\mathrm{Fe}^{3+}$ or $\mathrm{Co}^{2+}$ introduced in porous silicon (PS) layer may provide new nano-materials with optical, electrical and magnetic properties. Doping methods such as immersion or electrodeposition are currently used and must be followed by a thermal treatment in order to promote the insertion of the transition-metal ions inside the porous matrix and to form metal oxides at the porous surface.

Some investigations [2-4] have focused on the PL variation of porous silicon as a function of annealing temperature. Among these studies Roy et al. [2], reported that the PL peak position and the PL intensity have non-monotonic variations with increasing temperature. They indicated also that the origin of the PL can be explained by a model which incorporates both nanostructures for quantum confinement and silicon complexes with defects interfaces as luminescent centers. In another work, Wiemer et al. [3] have investigated the effects of annealing temperature and surface preparation on the formation of cobalt silicide interconnects. The authors reported that Raman peaks detected between 200 and $230 \mathrm{~cm}^{-1}$ were corresponding to a $\mathrm{CoSi}$ layer formed using a rapid thermal process. In, another work which focused on the cobalt silicide films [4], the elaborated films were analyzed by Raman spectroscopy which showed an intense peak at $670 \mathrm{~cm}^{-1}$ attributed to cobalt oxide formed by oxygen from air and the unreacted cobalt on the sample surface. From these different works, we noted that the cobalt-silicon layer has interesting physical properties such as a high thermal stability and a low bulk resistivity and then it can be employed for several applications in microelectronics and optoelectronics.

In this paper, we have introduced cobalt ions in the PS matrix and we have focused our interest on the effect of the annealing temperature on the optical properties of cobalt-porous silicon (PS/Co) nanocomposites using photoluminescence (PL) spectroscopy. Furthermore, we have followed the surface modifications of PS and PS/Co samples with temperature variation using FTIR spectroscopy. These modifications have been confirmed, also, by 
Raman spectroscopy. Complementary studies using Energy dispersive X-ray analysis were carried out to estimate the cobalt concentration through the depth of the porous layer.

\section{2- Experimental}

Samples were elaborated from a boron-doped p-type $\operatorname{Si}(100)$ substrates with $0.1-2 \Omega \mathrm{cm}$ resistivity. Firstly, an ohmic contact has been formed by coating the backside of the silicon wafer with aluminum (Al) and subsequently annealed at $500^{\circ} \mathrm{C}$ for $30 \mathrm{~min}$. The porous silicon was prepared using electrochemical anodisation in $\mathrm{HF}$ solution $(40 \%) / \mathrm{C}_{2} \mathrm{H}_{5} \mathrm{OH} / \mathrm{H}_{2} \mathrm{O}$ (2:1:1), the current density was $10 \mathrm{~mA} / \mathrm{cm}^{2}$ and the etching duration was fixed at $10 \mathrm{~min}$. The freshly PS layer was then immersed in an aqueous solution of cobalt chloride with a low concentration fixed at $0.5 \mathrm{M}$ during an optimal duration of $120 \mathrm{~min}$, maintained at RT. To eliminate the residual molecules and gases, the samples have been dried by nitrogen gas. For a thermal treatment in air, the sample was introduced in a programmable furnace maintained at the desired annealing temperature during $5 \mathrm{~min}$. Then, it was taken out of the furnace and cooled to RT in order to record both Raman and PL spectra at the same spot of the sample. The Raman and PL spectra were recorded using a micro-Raman spectrometer (Jobin-Yvon confocal micro-Raman T64000) with a resolution of $0.1 \mathrm{~cm}^{-1}$ and the recording time was set equal to 60s. The pumping source for PL and Raman measurements was the $488 \mathrm{~nm}$ argon laser line fixed at a power of $50 \mathrm{~mW}$. The FTIR analyses are taken on transmittance mode and investigated in the $400-4000 \mathrm{~cm}^{-1}$ range with a $2 \mathrm{~cm}^{-1}$ step using Bruker IFS66v/s FTIR spectrometer. In order to estimate the Co atomic percentage (at\%) in the porous layer, scanning electronic microscopy (SEM) observations and energy dispersive X-Ray (EDX) analysis were performed on the cross section of the sample at different depths using a JEOL JSM-5600 LV. The estimated error for each concentration variation was at most $0.3 \%$ taking into account the doping inhomogeneity of the sample. The scanned surface is about $1 \mu \mathrm{m}^{2}$ with a resolution of $1 \mu \mathrm{m}$.

\section{3- Results and discussion}

The FTIR spectroscopy was performed at RT on PS/Co before and after annealing process and compared to that obtained on PS (figure1). 


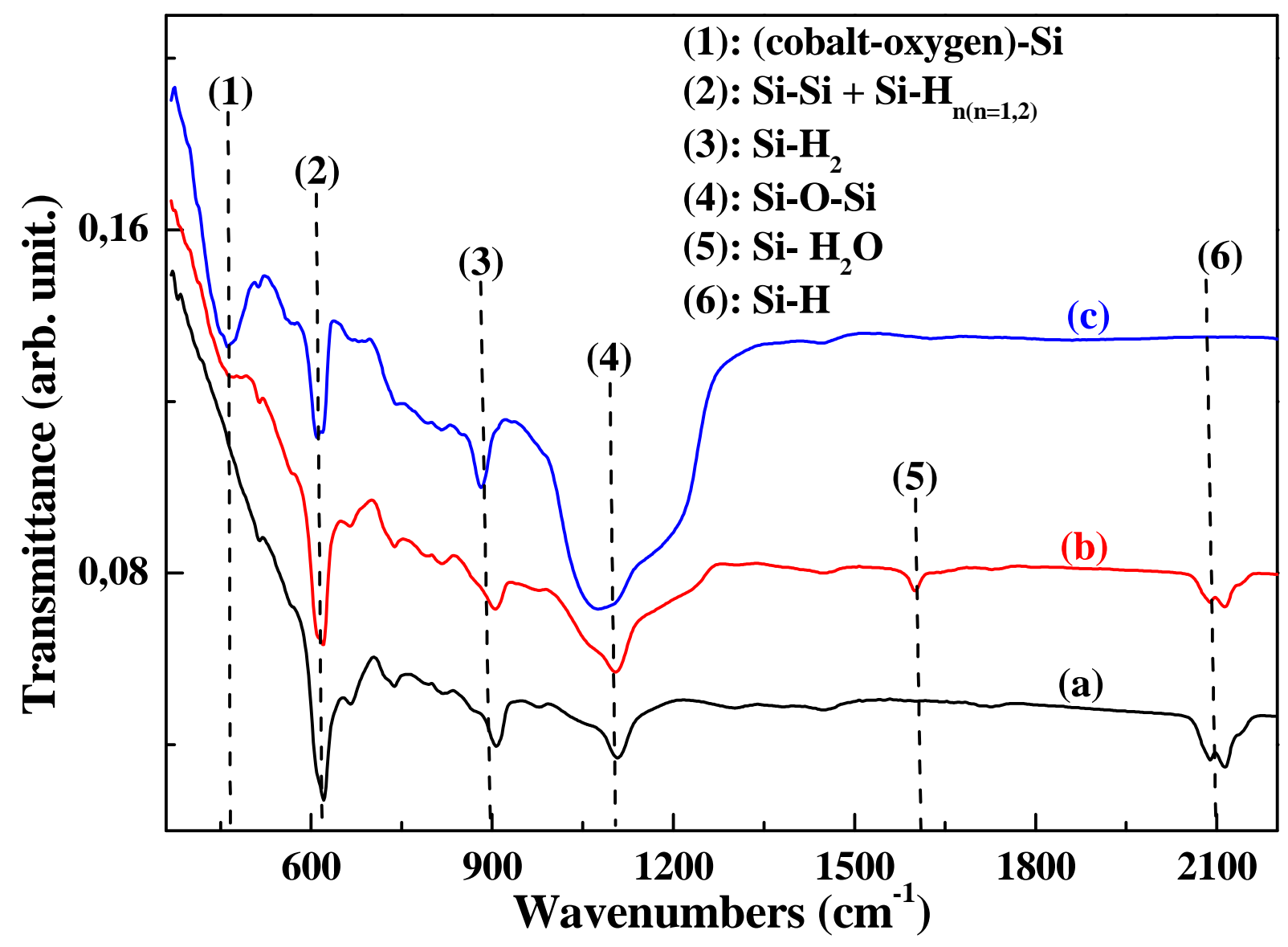

Figure 1: FTIR spectra of PS (a), PS/Co before annealing (b) and PS/Co after annealing at $400^{\circ} \mathrm{C}(\mathrm{c})$.

For PS, the principal recorded vibration bands are located at $620 \mathrm{~cm}^{-1}$ which is related to a

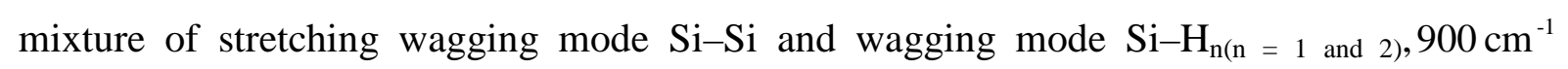
attributed to scissors mode $\mathrm{Si}-\mathrm{H}_{2}$. A large vibration absorption band is observed at $1100 \mathrm{~cm}^{-1}$ corresponding to stretching mode $\mathrm{Si}-\mathrm{O}-\mathrm{Si}$. Moreover, the spectrum also shows the presence of a vibration band at $2120 \mathrm{~cm}^{-1}$ indicating the presence of $\mathrm{Si}-\mathrm{H}$ bond in which the $\mathrm{Si}$ atom is back bonded to another $\mathrm{Si}$ atom [5-6]. A new vibration band at $470 \mathrm{~cm}^{-1}$ was appeared after PS immersion in $\mathrm{CoCl}_{2}$ aqueous solution. Generally, (metal-oxygen)-silicon bonding is expected between 300 and $700 \mathrm{~cm}^{-1}$ [5, 7-9], therefore the band at $470 \mathrm{~cm}^{-1}$ can be attributed to (cobalt-oxygen)-silicon bonding. We also observe a band at $1600 \mathrm{~cm}^{-1}$ corresponding to molecular water vibration [7], these species coming from the aqueous solution. After annealing process, the intensity of the band at $470 \mathrm{~cm}^{-1}$ has increased indicating the formation of a large quantity of cobalt oxide. We also observe, for higher annealing temperatures $\left(\mathrm{T}=400^{\circ} \mathrm{C}\right)$, the disappearance of the band corresponding to molecular water and the increase of the Si-O-Si vibration band. On the other hand, the annealing process does not 
affect the $\mathrm{Si}-\mathrm{Si}$ and $\mathrm{Si}-\mathrm{H}_{2}$ vibrations. This result indicates that $\mathrm{Si}-\mathrm{H}_{2}$ bonds remained at temperature more than that found in the case of the adsorption on $\operatorname{Si}(100)$ surface [10].

To confirm the FTIR results, SEM observations and EDX analysis were performed on the cross-section of PS. The results show that the porous layer thickness was about $6 \mu \mathrm{m}$. The EDX analysis, performed at different depth of PS/Co layer before and after annealing at $400^{\circ} \mathrm{C}$, reveals that the atomic percentage of cobalt decreased from the top to the bottom of the layer (Figure 2).

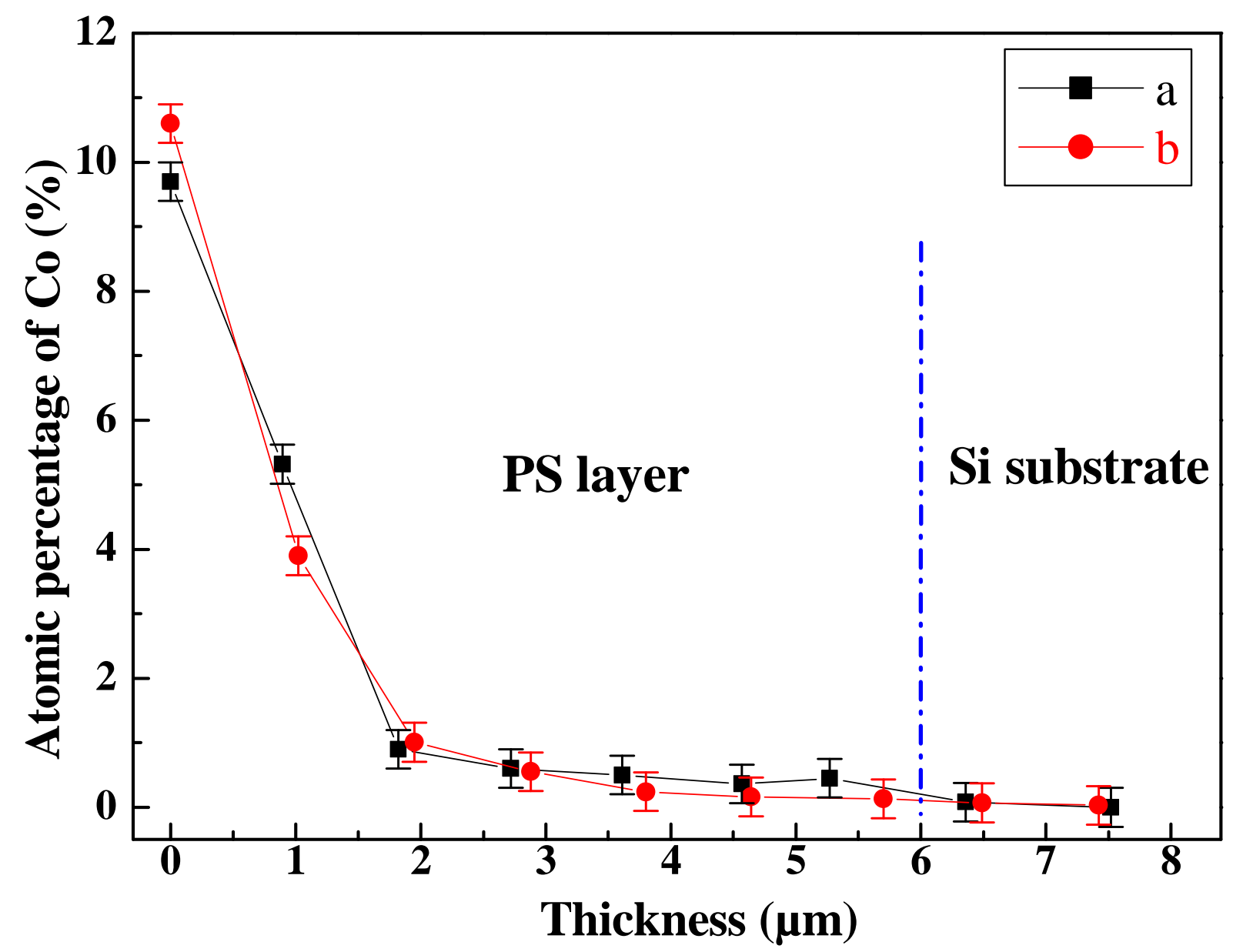

Figure 2: Atomic percentage of cobalt at different depths of the PS/Co layer from the top surface to the Si substrate deduced from EDX measurements: before annealing (a) and after annealing at $400^{\circ} \mathrm{C}(\mathrm{b})$.

The large amount of Co is deposed at the surface. The Cobalt concentration in the porous layer highly decreases up to a thickness of $1 \mu \mathrm{m}$. Then, it is difficult to confirm the presence of the cobalt since the measurement uncertainty is $0.2 \%$. These analyses well prove the presence 
of cobalt in the PS layer after immersion. The evolution of the atomic percentage of Co through the porous layer at $400^{\circ} \mathrm{C}$ has the same behavior as that found before annealing and the Co quantity was quietly preserved (figure 2). Hence, during annealing temperature up to $400^{\circ} \mathrm{C}$, the Co quantity introduced in PS layer is unvaried.

Figure 3 presents the Raman spectra of PS and PS/Co samples before annealing. For PS, the principal recorded bands in PS spectrum are observed at $130 \mathrm{~cm}^{-1}, 310 \mathrm{~cm}^{-1}, 500 \mathrm{~cm}^{-1}$ and $930 \mathrm{~cm}^{-1}$.

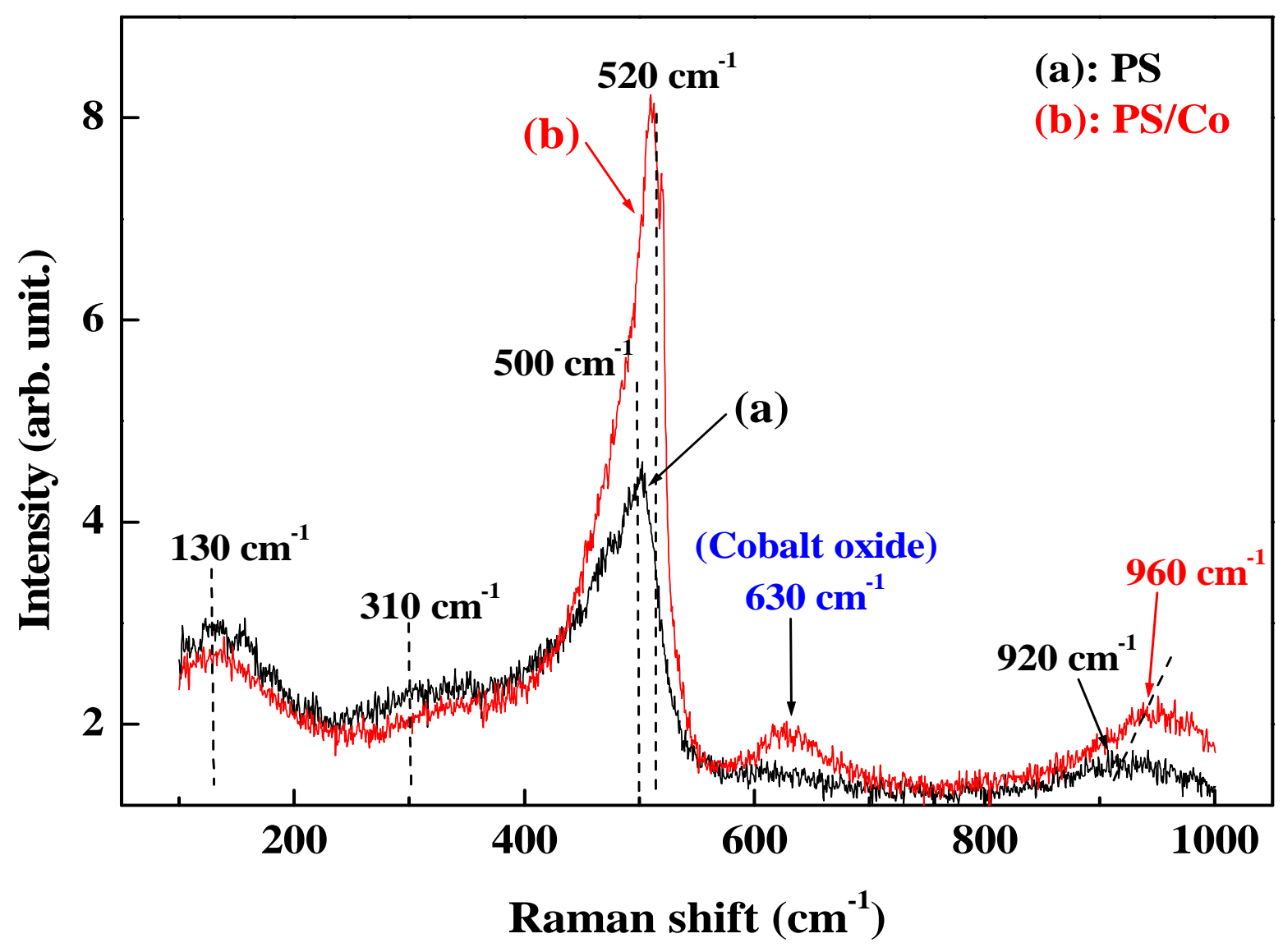

Figure 3: Raman spectra of unannealed PS and PS/Co.

This multiband profile has been attributed to the different phonons existing in the silicon matrix network [11]. Generally, the bands observed in the range of $900-1000 \mathrm{~cm}^{-1}$ are assigned to Si-OH stretching band [12-13], then the weak intensity of the observed in PS at $930 \mathrm{~cm}^{-1}$ would indicate the existence of a low quantity of hydrogen and oxygen elements at the porous surface. However, for PS/Co, the intensity of this band was increased and its position was slightly shifted to higher energies; we attributed this result to the growth of other 
$\mathrm{OH}$ bonds under immersion effect. In fact, Dixon and Gole [14] have suggested that the presence of $\mathrm{H}_{2} \mathrm{O}$ molecules with $\mathrm{Si}=\mathrm{O}$ induces the formation of $\mathrm{Si}(\mathrm{OH})$ groups. In addition, the $\mathrm{Si}-\mathrm{OH}$ bonds can be formed from bridging $\mathrm{O}$ atoms according to the equation:

$$
\mathrm{Si}-\mathrm{O}-\mathrm{Si}+\mathrm{H}_{2} \mathrm{O} \rightarrow \mathrm{Si}-\mathrm{OH}+\mathrm{HO}-\mathrm{Si}[12]
$$

For both samples, it can be seen that the main Raman peak in the range of $480-520 \mathrm{~cm}^{-1}$ is asymmetrically broadened. This result is in conformity with that reported by Papadimitriou [15], and it is related to the variation of nanocrystal diameters. According to other works [1618], the wavevectors of phonons (q) are not restricted to $q=0$ but they are extended from 0 to $\frac{\hbar}{\mathrm{L}}$ where $\mathrm{L}$ is the $\mathrm{Si}$ nanocristallites (nc-Si) size, the vibration frequency is written as:

$$
\omega(\mathrm{q})=\omega_{0}-\mathrm{aq}^{2}
$$

$\omega_{0}$ is the vibration frequency for perfect crystal $(q=0)$ and $a=2.310^{-14} \mathrm{~cm}$. From this relationship, the calculated average size of nc-Si at RT was about $2 \mathrm{~nm}$.

After the PS immersion in $\mathrm{CoCl}_{2}$ aqueous solution, the main modification was the apparition of a new band at $630 \mathrm{~cm}^{-1}$. Many authors $[4,13]$ have reported that the metal oxide vibration is expected in Raman spectrum between 600 and $700 \mathrm{~cm}^{-1}$. So, the new band at $630 \mathrm{~cm}^{-1}$ could be due to the change at the surface bonds of PS nanocomposites and it could be attributed to the existence of cobalt oxide molecules on PS layer. This hypothesis is confirmed by the EDX and FTIR analyses. We also noted that this band was broad which could indicate the existence of different cobalt oxides. According to Tang et al. [19], these oxides may be $\mathrm{CoO}(\mathrm{OH}), \mathrm{CoO}$ and $\mathrm{Co}_{3} \mathrm{O}_{4}$.

The effect of the annealing temperature on the Raman spectrum of PS is presented in figure 4. 


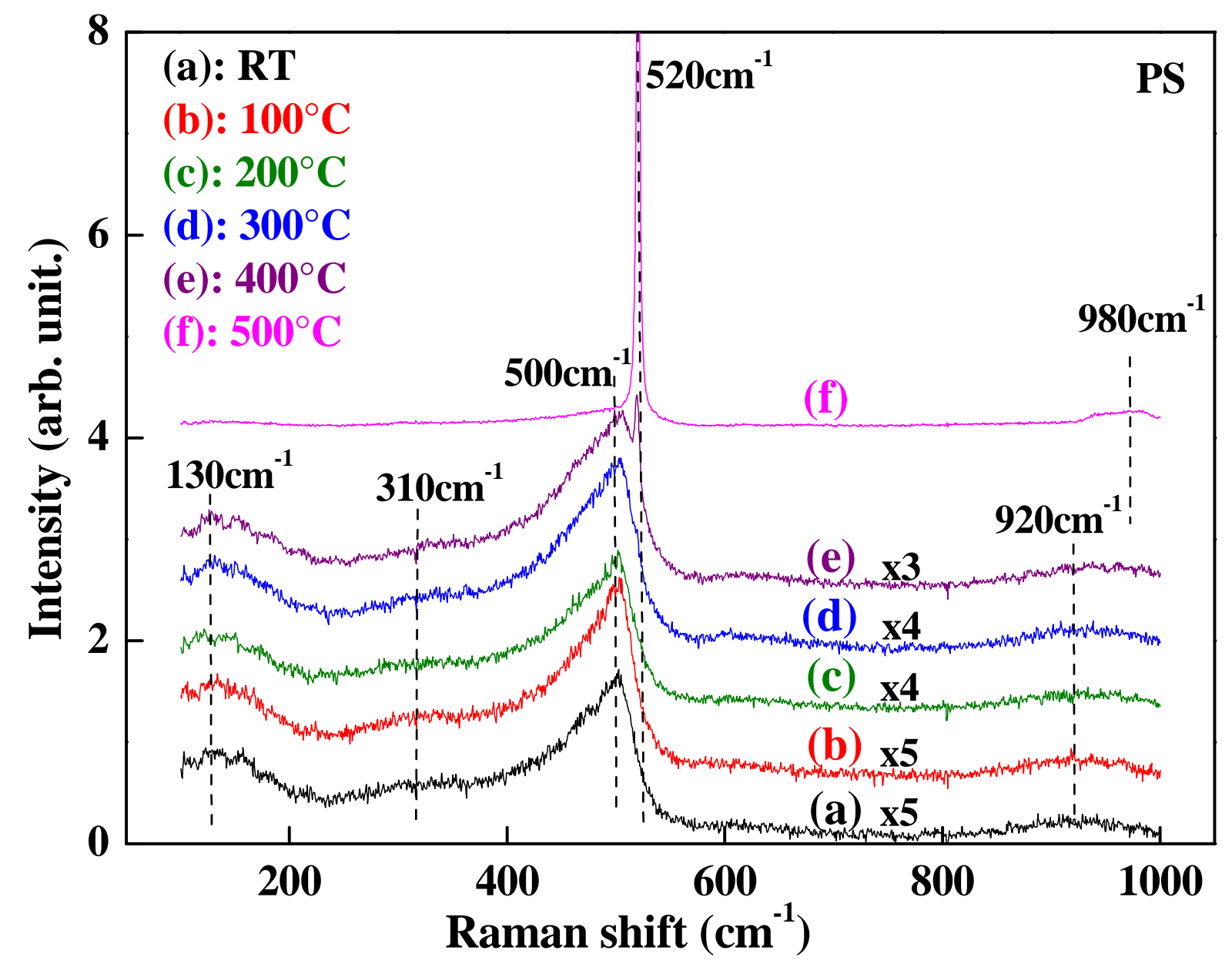

Figure 4: Raman spectra of PS at different annealing temperatures.

The bands corresponding to the vibration of the $\mathrm{Si}$ network, recorded at $130 \mathrm{~cm}^{-1}$ and $310 \mathrm{~cm}^{-1}$, decrease with annealing temperature. For temperature higher than $300 \mathrm{~cm}^{-1}$, the vibration band occurs near $500 \mathrm{~cm}^{-1}$ with broadening line width which decreases to the detriment of that at $520 \mathrm{~cm}^{-1}$; this later band also becomes be very sharp and intense at annealing temperature of $500 \mathrm{~cm}^{-1}$. This peak has the same Raman shift as the bulk silicon which corresponds to transversal optical (TO) vibration mode [20]. The band centered at $980 \mathrm{~cm}^{-1}$ is attributed to silica $\left(\mathrm{SiO}_{3}\right)$ [21]. At $500^{\circ} \mathrm{C}$, the porous silicon is completely oxidized and is transformed to silica. So, the annealing treatment modifies the crystallites size of the PS structure and leads to the formation of the oxide silicon.

In the case of PS/Co sample, the main Raman peak in the range of $500-520 \mathrm{~cm}^{-1}$ and the bands located at $130 \mathrm{~cm}^{-1}$ and $310 \mathrm{~cm}^{-1}$ have approximately the same behavior with the annealing temperature as that of the PS (figure 5). 


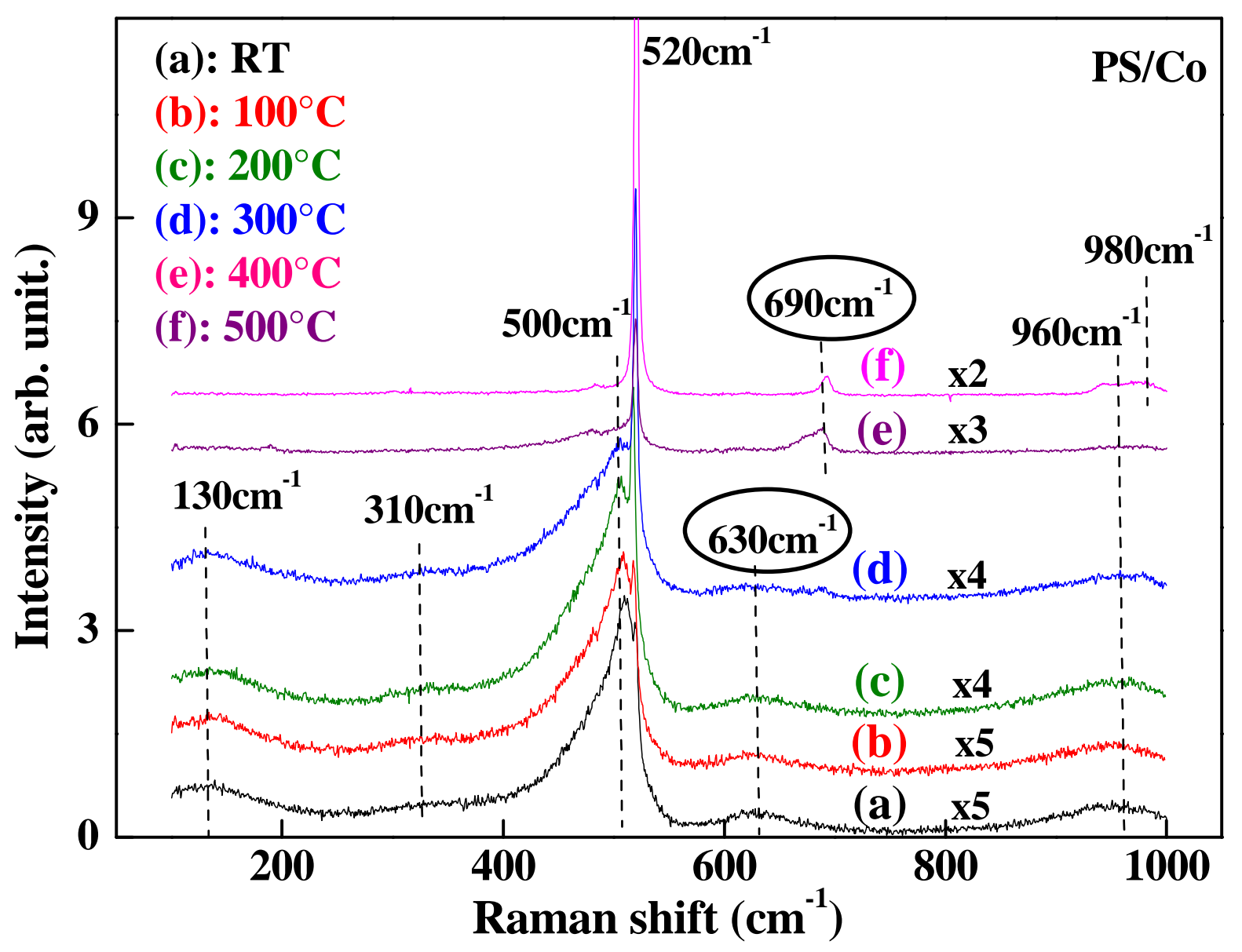

Figure 5: Raman spectra of PS/Co at different annealing temperatures.

For temperatures lower than $300^{\circ} \mathrm{C}$, the band at $630 \mathrm{~cm}^{-1}$ decreases progressively and beyond this temperature, a new band at $690 \mathrm{~cm}^{-1}$ appears. This new band is due to the transformation of $\mathrm{CoO}(\mathrm{OH})$ and $\mathrm{CoO}$ molecules to $\mathrm{Co}_{3} \mathrm{O}_{4}$ ones [19]. Then at $500^{\circ} \mathrm{C}$, there are two peaks situated at $520 \mathrm{~cm}^{-1}$ and $690 \mathrm{~cm}^{-1}$ and there is also a weak band centered at $980 \mathrm{~cm}^{-1}$. The Raman results show that the presence of cobalt in the PS matrix modifies the chemical composition of the nc-Si surface and an important role was played by the annealing process on the structure of the PS and PS/Co layers.

Figure 6 exhibits the PL spectra of PS and PS/Co prepared at different immersion durations $\left(\mathrm{t}_{\mathrm{imm}}\right)$, showing the stabilization of the PL peak position at $1.68 \mathrm{eV}$ and the enhancement of the PL intensity of PS/Co up to $\mathrm{t}_{\mathrm{imm}}$ equal to $60 \mathrm{~min}$. Then, beyond this time, the PL peak blue shifted and the PL intensity decreased with an increase of $t_{\mathrm{imm}}$. For a $\mathrm{t}_{\mathrm{imm}}$ of $240 \mathrm{~min}$ the $\mathrm{PL}$ peak of PS/Co is situated at $1.75 \mathrm{eV}$. 


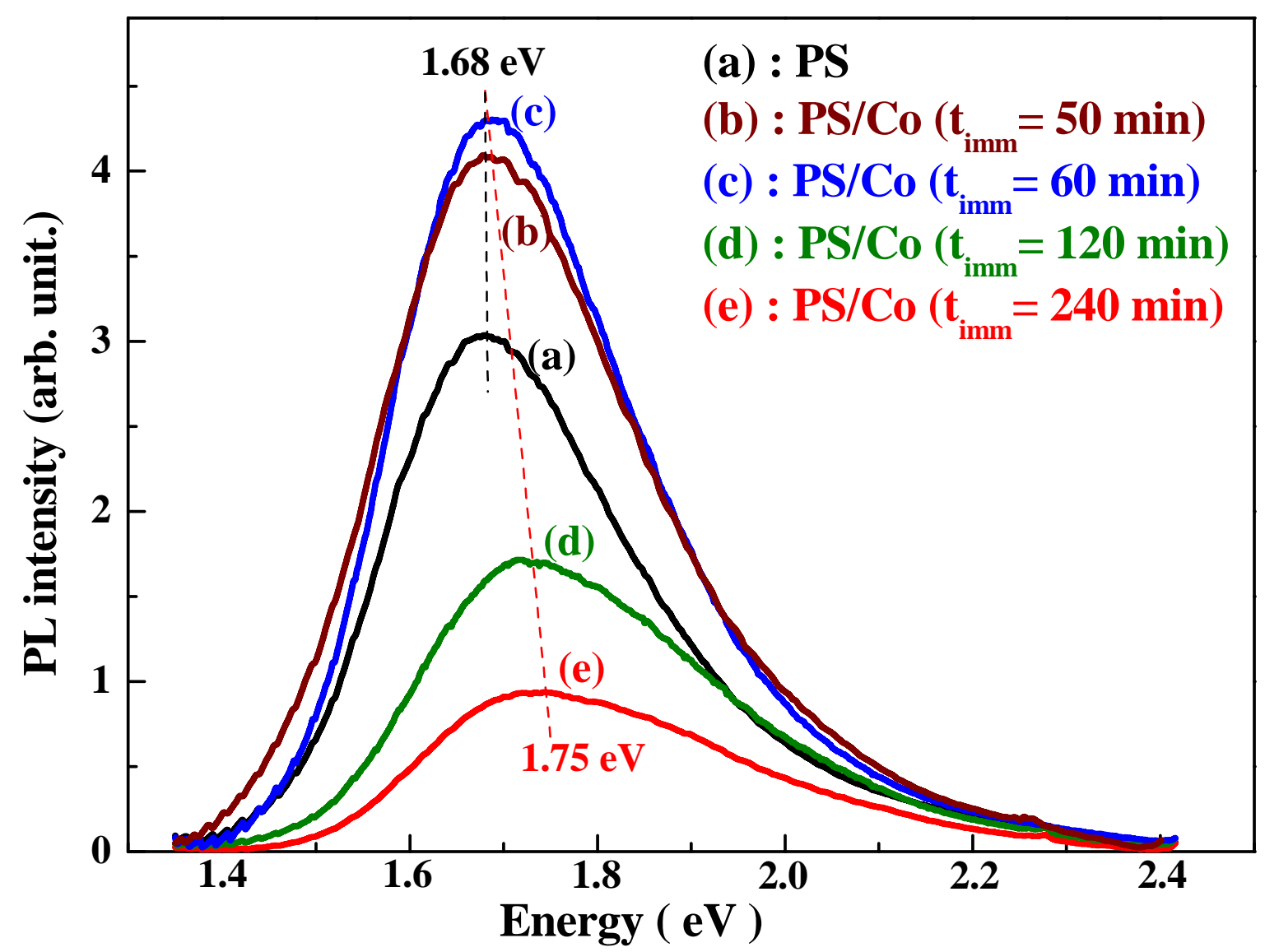

Figure 6: PL spectra of PS and PS/Co samples with different immersion durations in $\mathrm{CoCl}_{2}$ aqueous solution.

This behavior is quite similar to the effect of the iron incorporation in the porous silicon matrix [5]. These results would confirm that the presence of cobalt in PS matrix may modify the surface electronic structure by creating a new radiative recombination centers. While, for longer immersion durations, the large cobalt quantity deposited on the porous layer promotes the non-radiative energy transfer by creating excitation energy traps which induce the decrease of the PL intensity. This behavior is well known as autoextinction phenomenon [2223]. Furthermore, the large quantity of cobalt deposited on the nc-Si induced changes on their distribution and their sizes which explain the blue shift observed for a long $t_{\mathrm{imm}}$. Following this study, we will focus our interest on the PS sample immersed in $\mathrm{CoCl}_{2}$ solution for $60 \min$.

The effect of the annealing process on the PL of PS is presented in figure 7. 


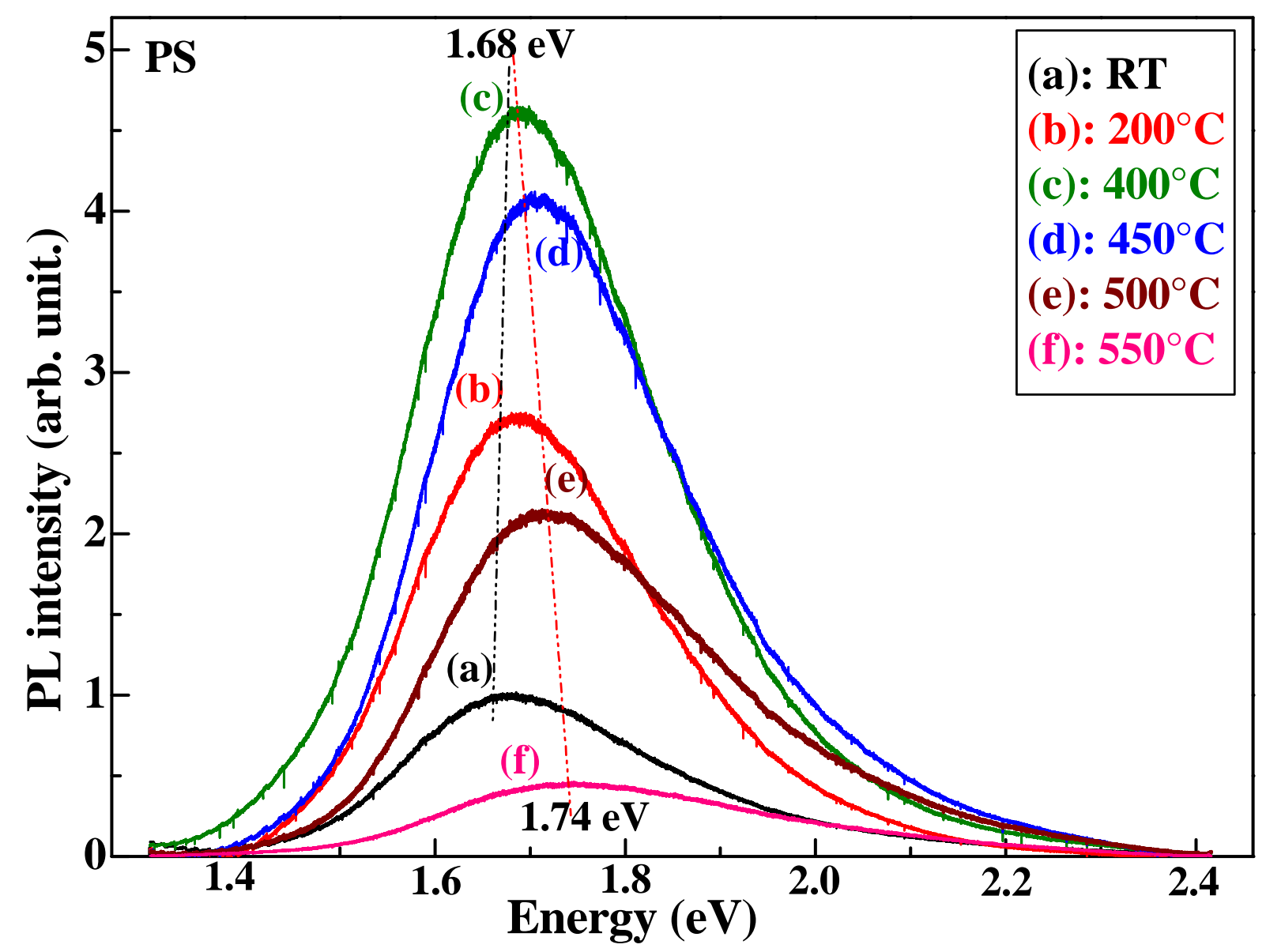

Figure 7: PL spectra of PS at various annealing temperatures.

It can be seen, from this figure, that the PL intensity increases keeping the same peak position $(1.68 \mathrm{eV})$ up to $400^{\circ} \mathrm{C}$ and then the PL spectrum blue-shifted and its intensity is decreased with increasing annealing temperature. We note, from $400^{\circ} \mathrm{C}$ to $550^{\circ} \mathrm{C}$, that the shift of the PL peak is about $60 \mathrm{meV}$. Roy et al. [2] have reported that, the annealing treatment promoted the formation of luminescent centers which can be point defects located at the $\mathrm{Si} / \mathrm{SiO}_{2}$ interface or in the thin $\mathrm{SiO}_{2}$ layers. In our case, we attributed the increase of the PL intensity to the oxide layer formed on the PS surface after the annealing treatment which generates a radiative recombination centers. In fact, the emission mechanism can be explained by the quantum confinement effect in nanocrystal and by the trap states in the interface between the oxide and the silicon nanocrystal. For higher temperatures $\left(\succ 400^{\circ} \mathrm{C}\right)$, the diffusion of oxygen in the inner of nc-Si has two effects: (i) the destruction of a part of the nc-Si which explains the decrease of the PL intensity; (ii) the decreasing in size of the remained nc-Si causing the 
observed blue shift. We can also attributed the shift to higher energies by the recombination of electrons trapped at the located states due to $\mathrm{Si}=\mathrm{O}$ bond of PS [5]. Furthermore, Gole et al [24-26] have reported that the change of the recombination paths can be attributed to silanone groups formed on the PS surface.

Figure 8 displays the PL spectra of PS/Co with $t_{\text {imm }}$ fixed at $60 \mathrm{~min}$ as a function of annealing temperature from RT to $550^{\circ} \mathrm{C}$.

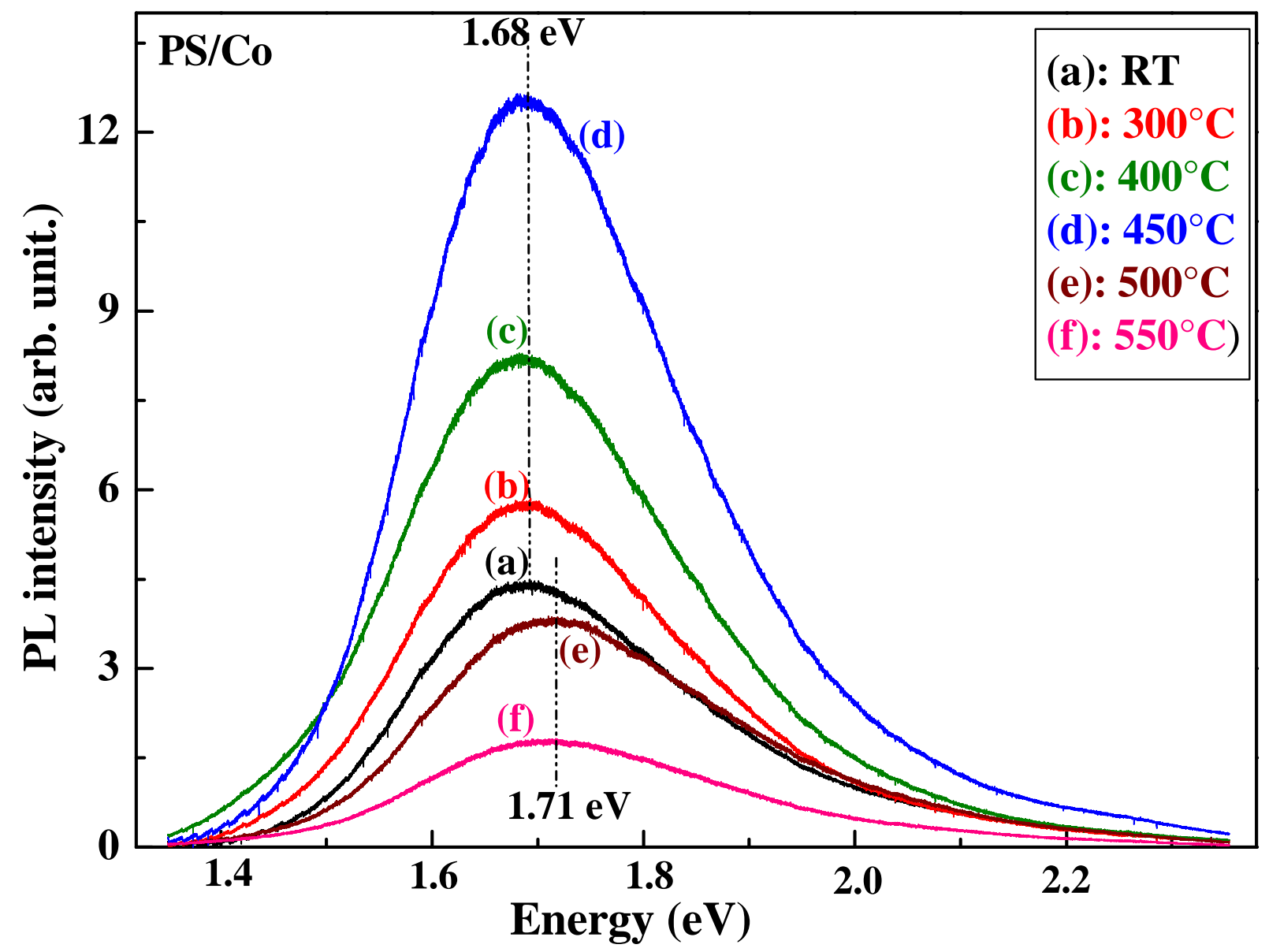

Figure 8: PL spectra of PS/Co at various annealing temperatures, the immersion duration is fixed at $60 \mathrm{~min}$.

This figure well shows that the PL peak position remains constant at $1.68 \mathrm{eV}$ till $450^{\circ} \mathrm{C}$ while the PL intensity increases and it will be three times higher at $450^{\circ} \mathrm{C}$. Above this temperature, the PL intensity decreases and the PL peak is slightly shifted to $1.71 \mathrm{eV}$. Remember that the PL intensity decreases rapidly from $400^{\circ} \mathrm{C}$ for PS sample, then for this annealing temperature we can distinguish the effect of cobalt oxide on the optical properties of PS. It is well known that the surface of as-prepared PS is terminated by H-related species. After immersion in the $\mathrm{CoCl}_{2}$ solution, the cobalt ions are adsorbed on the PS surface, and 
therefore the PS surface is covered by $\mathrm{H}$ and Co atoms. Usually, desorption of hydrogen takes place during annealing process, the unstable H-passivated surface is progressively replaced by stable O-passivated surface [27] and the cobalt is oxidized forming $\mathrm{CoO}(\mathrm{OH}), \mathrm{CoO}$ and $\mathrm{Co}_{3} \mathrm{O}_{4}$ molecules according to Raman study. Contrary to PS, The oxidation of the majority of $\mathrm{nc}-\mathrm{Si}$ is not evident owing to the presence of Co on nc-Si surfaces. Indeed, the cobalt protects the nc-Si by reacting with oxygen and forming the cobalt oxide on the nc-Si surfaces. The progressive chemical changes on the PS layer are characterized by an increase of the PL intensity till $450^{\circ} \mathrm{C}$. For higher temperatures, parts of radiative centers may be destroyed and the PS is transformed to silica which results in a decrease of the PL intensity. The shift of the PL spectra to $1.71 \mathrm{eV}$ is due to the diffusion of oxygen in the nc-Si and the transformation of the different cobalt oxide $\mathrm{CoO}(\mathrm{OH})$ and $\mathrm{CoO}$ to $\mathrm{Co}_{3} \mathrm{O}_{4}$. Therefore, the presence of the $\mathrm{Co}$ oxide molecules on the PS surface amends the chemical composition of the porous layer which affects the optical properties of this material.

\section{4- Conclusion}

Raman and PL of the annealed PS without and with Co have been studied. The conjugation of the different results shows that the annealing process of PS leads to a rapid diffusion of oxygen in the inner of nc-Si. This diffusion modifies the crystallite size explaining the PL peak shift. The immersion of PS in $\mathrm{CoCl}_{2}$ solution promotes the formation of three types of cobalt oxide molecules $\left(\mathrm{CoO}(\mathrm{OH}), \mathrm{CoO}\right.$ and $\left.\mathrm{Co}_{3} \mathrm{O}_{4}\right)$ on PS layer. These cobalt oxides are characterized by a Raman band shift located between 630 and $690 \mathrm{~cm}^{-1}$. The annealing temperatures higher than $300^{\circ} \mathrm{C}$ promote the transformation of $\mathrm{CoO}(\mathrm{OH})$ and $\mathrm{CoO}$ molecules into $\mathrm{Co}_{3} \mathrm{O}_{4}$ ones and beyond $500^{\circ} \mathrm{C}$ the porous silicon is transformed to silica. In the other hand, the chemical changes of the porous surface after immersion in $\mathrm{CoCl}_{2}$ solution affect the luminescence properties of the PS, the cobalt ions generate a radiative recombination centers which enhance the PL intensity without changing the PL peak position. For immersion duration of $60 \mathrm{~min}$, the PL intensity of PS/Co is enhanced more than three times compared to that of PS. The PL intensity of PS/Co sample continues to increase with annealing temperature till $450^{\circ} \mathrm{C}$, and then it decreases and finally it disappears at $600^{\circ} \mathrm{C}$. The PL behavior of PS and PS/Co is due to two causes; for PS, there is an O-passivation of nc-Si at $\mathrm{T} \leq 400^{\circ} \mathrm{C}$ and at $\mathrm{T} \geq 400^{\circ} \mathrm{C}$, the oxygen is diffused in nc-Si while for PS/Co, the cobalt oxides prevent the nc-Si from oxidation up to $450^{\circ} \mathrm{C}$ and there is a transformation of 
$\mathrm{CoO}(\mathrm{OH})$ and $\mathrm{CoO}$ to $\mathrm{Co}_{3} \mathrm{O}_{4}$. At $\mathrm{T} \geq 400^{\circ} \mathrm{C}$ a progressive destruction of radiative centers and a transformation of PS layer to silica occur.

\section{Acknowledgements}

The authors would like to thank Prof. Radouane Chtourou (Laboratoire de Photovoltaïque et de Semi-conducteurs, centre de recherche et de technologie de l'énergie, Hammam Lif Tunisia) for FTIR measurements. The authors acknowledge also Prof. Mohamed Guendouz and Prof. Adel Moadhen for helpful discussions. 


\section{References:}

[1]: L. T. Canham, Appl. Phys. Lett., 57 (1990) 1046.

[2]: A. Roy, K. Jayaram and A. K. Sood, Solid State Communications, 89 (1994) 229.

[3]: C. Wiemer, G. Tallarida, E. Bonera, E. Ricci, M. Fanciulli, G.F. Mastracchio, G. Pavia, S. Marangon, Microelectronic Engineering 70 (2003) 233.

[4]: F.M. Liu, J.H. Ye, B. Ren, Z.L. Yang, Y.Y. Liao, A. See, L. Chan, Z.Q. Tian, Thin Solid Films 471 (2005) 257.

[5]: M. Rahmani, A. Moadhen, M.-A. Zarbi, H. Elhouichet, M. Oueslati, Journal of Luminescence 128 (2008) 1763.

[6]: T.I. Gorbanyuk, A.A. Evtukh, V.G. Litovchenko, V.S. Solnsev, E.M. Pakhlov, Thin solid films 495 (2006) 134.

[7]: C.M. Parler, J.A. Ritter, M.D. Amiridis, J. Non-Cryst. Solids 279 (2001) 119.

[8]: F. Hamadache, C. Renaux, J.-L. Duvail, P. Bertrand, Phys. Status Solidi (a) 197 (2003) 168.

[9]: M. Miu, I. Kleps, T. Ignat, M. Simion, A. Bragaru, Journal of Alloys and Compounds 496 (2010) 265.

[10]: P. Martin, J.F. Fernandez, C. Sanchez, Materials Science and Engineering B108 (2004), 166.

[11]: R.C. Pedroza, S.W. da Silva, M.A.G. Soler, P.P.C. Sartoratto, D.R. Rezende, P.C. Morais, Journal of Magnetism and Magnetic Materials 289 (2005) 139-141.

[12]: Nikolay Zotov, Hans Keppler, American Mineralogist 83 (1998) 823.

[13]: S.W. da Silva, R.C. Pedroza, P.P.C. Sartoratto, D.R. Rezende, A.V. da Silva Neto, M.A.G. Soler, P.C. Morais, Journal of Non-Crystalline Solids 352 (2006) 1602.

[14]: David A. Dixon and James L. Gole, J. Phys. Chem. B 109 (2005) 14830.

[15]: D. Papadimitriou, J. Bitsakis, J.M. Loâpez-Villegas, J. Samitier, J.R. Morante, Thin Solid Films 349 (1999) 293.

[16]: K. H. Khoo, A. T. Zayak, H. Kwak, and James R. Chelikowsky, Phys. Rev. Lett. 105 (2010) 115504.

[17]: C. S. Chang, J. T. Lue, Thin Solid Films 259 (1995) 275.

[18]: Giuseppe Faraci, Santo Gibilisco, and Agata R. Pennisi, Phys. Rev. B 80 (2009) 193410.

[19]: C.-W. Tang, C.-B. Wang, S.-H. Chien, Thermochimica Acta, 473 (2008) 68. 
[20]: M. Rahmani, A. Moadhen, M.-A. Zaibi, A. Lusson, H. Elhouichet, M. Oueslati, Journal of Alloys and Compounds 485 (2009) 422-426.

[21]: J. Hanuza, M.Ptak, M.Maczka, K.Hermanowicz, J.Lorenc, A.A.Kaminskii, Journal of Solid State Chemistry 191 (2012) 90.

[22]: G.S. Beddard, G. Porter, Nature 260 (1976) 366.

[23]: J. Knoester, J.E. Van Himbergen, J. Chem. Phys. 86 (6) (1987) 3571.

[24]: James L. Gole, Julie A. DeVincentis, Lenward Seals, Peter T. Lillehei, S. M. Prokes, David A. Dixon, Phys. Rev. B 61 (2000) 5615.

[25]: James L. Gole, David A. Dixon, Phys. Rev. B 57 (1998) 12002.

[26]: James L. Gole, Erling Veje, R. G. Egeberg, A. Ferreira da Silva, I. Pepe, David A. Dixon, J. Phys. Chem. B 110 (2006) 2064.

[27]: Y. Zhao, D. Li, W. Sang, D. Yang, Solid-State Electronics 50 (2006) 1529. 